\title{
Release of an oxytocic peptide at parturition in the marsupial, Macropus eugenii
}

\author{
L. J. Parry, F. J. Guymer, T. P. Fletcher and M. B. Renfree \\ Department of Zoology, University of Melbourne, Parkville, Victoria, 3052, Australia
}

\begin{abstract}
The oxytocic peptide mesotocin was measured in plasma samples collected throughout pregnancy in the conscious tammar wallaby, Macropus engenii. Plasma mesotocin and the prostaglandin metabolite 13,14-dihydro-15-oxo-prostaglandin $\mathrm{F}_{2 a}$ were also assessed immediately prepartum and during parturition. A radioimmunoassay for mesotocin was validated in the tammar and this assay allowed direct measurement in $50 \mu \mathrm{l}$ unextracted plasma with a sensitivity of $12.5 \mathrm{pmol} \mathrm{1}^{-1}$. Plasma concentrations of mesotocin remained basal (approximately $15 \mathrm{pmol}^{-1}$ ) at all stages of pregnancy, including prepartum. A significant $(P<0.05)$ increase in plasma mesotocin was observed only immediately after delivery of the neonate and this increase was maintained for at least 15 min postpartum. Mesotocin concentrations returned to basal values $2 \mathrm{~h}$ after birth. Peak concentrations of mesotocin of $516.7 \pm 108.1 \mathrm{pmol} \mathrm{I}^{-1}$ were measured within $2 \mathrm{~min}$ of birth. This peak coincided with a short-lived peak in concentration of prostaglandin $\mathrm{F}_{2 \alpha}$ metabolite immediately after birth $\left(2.1 \pm 0.4 \mathrm{nmol} \mathrm{l}^{-1}\right)$ which decreased to less than $0.3 \mathrm{nmol} \mathrm{l}^{-1}$ within $2 \mathrm{~h}$ postpartum. These data demonstrate that mesotocin is released during, or immediately after, delivery and appears to parallel the profile of circulating prostaglandin $\mathrm{F}_{2 \alpha}$ metabolite in this marsupial.
\end{abstract}

\section{Introduction}

The posterior pituitary peptide oxytocin plays an important role at birth in eutherian mammals. It is a potent stimulator of myometrial contractions via direct action on uterine smooth muscle, and indirect action on the endometrium to promote increased arachidonic acid metabolism and subsequent synthesis of prostaglandins $F_{2 a}$ and $E_{2}$ (Chan and Chen, 1992). Circulating concentrations of oxytocin remain low throughout pregnancy and do not increase until the onset of delivery, although small, irregular oxytocin pulses have been reported in early labour in rabbits (Fuchs and Dawood, 1980), women (Fuchs et al., 1991) and cattle (Aurich et al., 1993). A large increase in plasma oxytocin coincides with the expulsive phase of delivery in rats and rabbits (Fuchs, 1985; Higuchi et al., 1985; O'Byrne et al., 1986) and is associated with an increase in oxytocin neurone activity (O'Byrne et al., 1986). Release of oxytocin is preceded by a marked increase in oxytocin receptor concentrations in both the myometrium and endometrium in several species (Soloff, 1985; Fuchs, 1990; Fuchs et al., 1992). The action of oxytocin appears to be fundamental for parturition, as demonstrated in studies in rats and guinea-pigs using oxytocin receptor antagonists (Antonijevic et al., 1995; Schellenberg, 1995).

In eutherian mammals, the uterotonic effect of oxytocin is distinct from that of arginine (or lysine in artiodactyls) vasopressin which has strong pressor and antidiuretic properties. In most nonmammalian vertebrates, the equivalent neurohypophyseal hormones are mesotocin, which differs from oxytocin

Revised manuscript received I March 1996. only by a substitution of isoleucine for leucine at position 8 , and arginine vasotocin (Acher, 1990). However, the classic functions of oxytocin and arginine vasopressin both appear to be controlled by the one hormone vasotocin in those tetrapods investigated (Sawyer and Pang, 1979; Saito et al., 1991). Mesotocin is also the oxytocic peptide of Australian marsupials (Acher and Chauvet, 1995), whereas oxytocin is found in two South American marsupials (Chauvet et al, 1985) and in monotremes (Acher, 1990). Both peptides are present in the Australian bandicoot, Isoodon macrourus (Rouille et al., 1988; Bathgate et al., 1992) and North American opossum, Didelphis virginiana (Chauvet et al., 1984). Acher and Chauvet (1995) suggest that secondary duplications of the oxytocin gene with a subsequent single-step mutation may have led to the appearance of mesotocin in marsupials. The marsupial oxytocic receptor shows no pharmacological specificity for mesotocin over oxytocin (Sernia et al., 1991; Bathgate and Sernia, 1995a) as indicated by the similar response to these two peptides in vitro of the myometrium of late pregnant tammars (Bathgate et al., 1995). Moreover, the presence of oxytocic receptors in the uterus and median vaginal sacs of the lactating brushtail possum Trichosurus vulpecula (Sernia et al., 1991) indicates that, unlike nonmammalian vertebrates, mesotocin has an important uterotonic function in marsupials.

Female marsupials have two separate uteri, each of which has a separate cervix (Tyndale-Biscoe, 1966). At parturition, the fetus passes through the cervix into the median vagina and then reaches the urogenital opening via the urogenital sinus. As this birth-canal is several times longer than the fetus, contractions of the uterus and median vagina may be essential to achieve expulsion of the young. Prostaglandins are essential 
for normal parturition in tammars (Renfree et al., 1995). A surge in circulating prostaglandin metabolite 13,14-dihydro-15-oxoprostaglandin $\mathrm{F}_{20}$ (PGFM) occurs immediately before or at birth (Lewis et al., 1986). This is associated with an increase in the endometrial content of prostaglandins $\mathrm{F}_{2 \alpha}$ and $\mathrm{E}_{2}$, both of which stimulate uterine contractions in gravid uteri during late pregnancy in vivo (Shaw, 1983a). Data from a number of studies suggest that, as in eutherians, an oxytocic peptide is important for parturition in marsupials. Hypophysectomy in pregnant tammars does not disrupt the normal course of pregnancy or the function of the corpus luteum, but parturition does not occur. Fetuses are carried to term but are found dead in the uterus at autopsy (Hearn, 1973). Similar results have been reported in the brushtail possum (Hinds, 1990). The essential pituitary factor does not appear to be gonadotrophins (Short et al., 1985) or prolactin (Fletcher et al., 1990), as their absence does not affect parturition. Exogenous oxytocin induces contractions of both the gravid and nongravid uterus in vitro and in vivo in the pregnant tammar wallaby (Renfree and Young, 1979; Shaw, 1983b). Recent work has shown that continuous infusion of the oxytocin receptor antagonist atosiban in late pregnant tammars inhibits oxytocin- and mesotocininduced uterine contractions and delays birth (Renfree et al., in press), providing strong evidence for a physiological role for mesotocin in marsupial parturition.

The profile of mesotocin release and its association with other hormones secreted during the peripartum period, in particular prostaglandins, has not been established in conscious marsupials. Basal mesotocin concentrations have been reported in male and female brushtail possums (Bathgate et al., 1990) and bandicoots (Bathgate et al., 1992). In both studies, the reproductive status of the females was not specified and some of the animals were anaesthetized which may stimulate release of mesotocin (Bathgate and Sernia, 1995b). The aim of the present study was to measure plasma mesotocin concentrations in conscious female tammar wallabies throughout pregnancy and during parturition to determine the onset of mesotocin secretion and its relation to circulating prostaglandin $\mathrm{F}_{2 \alpha}$ metabolite.

\section{Materials and Methods}

\section{Animals}

Adult female tammar wallabies originally from Kangaroo Island (South Australia) were maintained in our captive breeding colony located at Monash University (Clayton, Victoria). Females were housed with males in the ratio of 1 male: 4 females in open grassy enclosures, with lucerne hay, fresh vegetables and water freely available. Husbandry, handling and experiments were in accordance with the National Health and Medical Research Council Australia/Commonwealth Scientific and Industrial Research Organisation/Australia Research Council Guidelines Australian Code of Practice for the Care and Use of Animals for Scientific Purposes, with approval from the University of Melbourne Animal Experimentation Ethics Committee and the Department of Conservation and Natural Resources (Victoria, Australia). Pregnancies were synchronized in tammars (body mass approximately $5 \mathrm{~kg}$ ) during February, early in the breeding season, by removing the pouch young
(RPY) from animals assumed to be carrying a blastocyst in embryonic diapause. Removal of the pouch young terminates lactational diapause, and the blastocyst and corpus luteum resume development. Births are expected between 26 and 27 days later (Renfree et al., 1989). The day of RPY was designated day 0 of pregnancy.

\section{Pituitary mesotocin}

Pituitary glands were collected from two adult female tammars in late pregnancy for use in validating the radioimmunoassay and to assess mesotocin content. The glands were removed immediately after the animals were killed by an overdose of sodium pentobarbitone; the posterior pituitary was separated from the anterior pituitary, weighed and stored at $-20^{\circ} \mathrm{C}$. The pituitary gland tissue was homogenized and extracted by the method of Bathgate et al. (1990) with minor modifications. Briefly, the supernatant was applied twice to C18 Sep-Pak cartridges (Millipore Waters Chromatography, Australia Millipore Pty Ltd, NSW) and mesotocin was eluted with $4 \mathrm{ml}$ of $80 \%(\mathrm{v} / \mathrm{v})$ acetonitrile in $0.1 \%(\mathrm{v} / \mathrm{v})$ trifluroacetic acid. Procedural losses were estimated by addition of 10000 c.p.m. of ${ }^{125}$ I-labelled mesotocin immediately before extraction; $99.5 \%$ of the ${ }^{125}$ I-labelled mesotocin was recovered in the first $3 \mathrm{ml}$ of eluate. The extract was reconstituted in $80 \mu \mathrm{I}$ $10 \%$ acetonitrile in $0.1 \%$ trifluoroacetic acid and loaded onto a Bondclone reverse phase HPLC column $(300 \mathrm{~mm} \times 7.8 \mathrm{~mm}$, Phenomenex, Torrance, CA). Peptides were eluted with a $10-30 \%$ acetonitrile gradient in $0.1 \%$ trifluoroacetic acid at a flow rate of $1 \mathrm{ml} \mathrm{min}{ }^{-1}$ over $30 \mathrm{~min}$. Fractions were collected at $20 \mathrm{~s}$ intervals and mesotocin immunoreactivity was measured by radioimmunoassay. The column was calibrated using oxytocin, mesotocin, isotocin, vasotocin and arginine vasopressin (Bachem UK Ltd, Saffron Walden, Essex). Retention times for arginine vasopressin, vasotocin, mesotocin, isotocin and oxytocin were 13.6 $\pm 0.1,15.8 \pm 0.1,17.6 \pm 0.1$, $18.0 \pm 0.2$ and $18.7 \pm 0.1 \mathrm{~min}$, respectively (mean $\pm \mathrm{SD}, n=8$ ).

\section{Mesotocin during pregnancy}

Pouch young were removed from five tammars known to have mated. A blood sample $(2.5 \mathrm{ml})$ was taken from a lateral tail vein, with the conscious animal lightly restrained in a sack, on day 0 of pregnancy and then every second day (between 09:00 and 10:00 h) until day 20 of pregnancy. From day 20 of pregnancy, daily blood samples were taken. The females' pouches were checked daily from day 25 of pregnancy for the presence of new born young. Blood samples were taken until birth or until day $30 \mathrm{RPY}$, when animals were presumed not to have been pregnant.

\section{Mesotocin during parturition}

Pouch young were removed from 14 tammars known to have mated. It was first necessary to establish that neither light physical restraint nor a frequent blood sampling procedure affected basal mesotocin concentrations in conscious pregnant 
tammars. Therefore, at $08: 00 \mathrm{~h}$ on day 19 of pregnancy, indwelling catheters (Jelco 18G, $32.0 \mathrm{~mm}$; Victoria Hospitals Association, Mulgrave, Victoria) were inserted into a lateral tail vein of five of the 14 animals. Serial blood samples $(0.75 \mathrm{ml})$ were taken at intervals of $1 \mathrm{~min}$ for a maximum of $20 \mathrm{~min}$, with the conscious animal lightly restrained in a sack. At the end of the sampling period, the catheters were removed and the animals were returned to their grassed enclosures. At 08:00 h on day 25 of pregnancy, a second catheter was inserted into the lateral tail vein of all 14 animals and a single blood sample $(2.5 \mathrm{ml})$ was taken. The animals were then placed into a separate, grassed enclosure illuminated by artificial lights from dusk until dawn and watched continuously for signs of birth. Intense pouch cleaning may occur up to $24 \mathrm{~h}$ before parturition. As birth approaches, the female licks the urogenital opening and shows indifferent behaviour towards other animals. Immediately before delivery, the female adopts a characteristic posture (Renfree et al., 1989), so birth can be anticipated. When an animal was observed in the birth position, it was caught and lightly restrained with a sack covering its head, leaving the hind quarters and tail free. This allowed the animal to retain the birth position, with the tail vein accessible for collection of blood samples via the indwelling catheter. The exact time of birth was recorded. Continuous observations ceased on day 28 RPY. The animals were checked daily until day 32 RPY for late births and signs of mating by the presence of a copulatory plug in the urogenital opening.

\section{Collection of blood samples}

All blood samples were collected into heparinized syringes and added to chilled polypropylene microcentrifuge tubes containing 2 mmol EDTA $1^{-1}$ to limit enzymatic breakdown of the peptide mesotocin. Blood samples were kept at $4^{\circ} \mathrm{C}$ for a maximum of $20 \mathrm{~min}$ before centrifugation at $1500 \mathrm{~g}$ for $15 \mathrm{~min}$. Plasma was collected and stored at $-70^{\circ} \mathrm{C}$ with $2 \mathrm{mmol}$ EDTA $1^{-1}$ until assay. In Exp I ( $n=6$ tammars), blood samples $(2.5 \mathrm{ml})$ were taken at intervals of $8 \mathrm{~h}$ commencing at $08: 00 \mathrm{~h}$ on day 25 of pregnancy until parturition for the assay of both mesotocin and PGFM. Samples were also taken at $20 \mathrm{~min}$, $40 \mathrm{~min}, \mathrm{I} \mathrm{h}, 2 \mathrm{~h}$ and $4 \mathrm{~h}$ after birth. In Exp II ( $n=8$ tammars), serial blood samples ( $1 \mathrm{ml}$ ) were taken at intervals of $1 \mathrm{~min}$ for a maximum of $20 \mathrm{~min}$ once the animal adopted a birth position for the assay of mesotocin only. Further samples were taken $40 \mathrm{~min}$ and $60 \mathrm{~min}$ after birth.

\section{Radioimmunoassays}

All samples from individual animals were measured in triplicate in a single assay. Plasma samples were assayed directly without extraction; samples from parturient animals were diluted with buffer (1:2) before assay.

Assay of mesotocin. Mesotocin was measured by a double antibody, heterologous radioimmunoassay. A Tris- $\mathrm{HCl}$ buffer containing $0.1 \mathrm{~mol}^{\text {Tris }} \mathrm{l}^{-1}, 0.1 \mathrm{~mol} \mathrm{HCl} \mathrm{l}^{-1}, 0.15 \mathrm{~mol} \mathrm{NaCl}$ $1^{-1}$ and $0.2 \%(w / v)$ BSA was used throughout the assay. The mesotocin antiserum, raised in rabbits, was a gift from $S$. Birkett (Dept of Anatomy, University of Bristol). Mesotocin antiserum at a final dilution of $1: 32000$ bound $30-40 \%{ }^{125}$ I-labelled mesotocin in the absence of unlabelled mesotocin and produced an appropriate standard curve to measure the range of mesotocin expected in the plasma. Specificity of the mesotocin antiserum was tested by estimating crossreactivity with related peptides. Relative crossreactivities were as follows: mesotocin: $100 \%$; isotocin: $40 \%$; oxytocin: $2.5 \%$; arginine vasopressin: $0.6 \%$; vasotocin: $0.075 \%$; melatonin $<0.01 \%$. A series of mesotocin standards $(6.25,12.5,25,50,100,200,400,800$, 1600,3200 and $6400 \mathrm{pmol} \mathrm{1}^{-1}$ ) was prepared for each radioimmunoassay. The radiolabelled mesotocin was iodinated using the Iodogen method (Fraker and Speck, 1978). The ${ }^{125}$ I-labelled mesotocin was separated from free iodide by stepwise elution from a C18 Sep-Pak (Australia Millipore Pty Ltd, NSW). Fractions with near maximum radioactivity and binding with the mesotocin antiserum were stored in $50 \mu \mathrm{l}$ aliquots at $-20^{\circ} \mathrm{C}$. The tracer had a specific activity in the range of $150 \mu \mathrm{Ci} \mu \mathrm{g}^{-1}$ and was used within a month of iodination. A sheep anti-rabbit IgG (Silenus Laboratories, Hawthorn, Victoria) was used to precipitate the antiserumbound hormone complex.

Assay procedure. Plasma samples $(50 \mu \mathrm{l})$ and standards $(50 \mu \mathrm{l})$ were added to $75 \mathrm{~mm} \times 11 \mathrm{~mm}$ polyethylene test tubes (Bio Lab, Rosebank, Clayton, Victoria) and incubated with $50 \mu \mathrm{l}$ mesotocin antiserum overnight at $4^{\circ} \mathrm{C}$. Fifty microlitres of ${ }^{125}$ I-labelled mesotocin (7000 c.p.m. per tube, 20 pg mesotocin) were then added to all tubes, vortexed and incubated overnight at $4^{\circ} \mathrm{C}$. Non-immune rabbit serum $(50 \mu \mathrm{l}$, dilution $1: 80)$ and sheep anti-rabbit $\operatorname{lgG}(100 \mu \mathrm{l}$, dilution $1: 40)$ were added to all tubes except Total Count tubes. All tubes were vortexed and incubated for $4 \mathrm{~h}$ at $4^{\circ} \mathrm{C}$. Separation of antiserum-bound ${ }^{125}$ I-labelled mesotocin from free ${ }^{125}$ I-labelled mesotocin was improved by addition of $1 \mathrm{ml} 4 \%(\mathrm{v} / \mathrm{v})$ polyethyleneglycol (PEG 6000: Ajax Chemicals, Crown Scientific, Burwood, Victoria) before centrifugation at $3500 \mathrm{~g}$ for $20 \mathrm{~min}$. The supernatant was aspirated and radioactivity in the antiserumbound pellet was counted in a 1470 Wizard gamma counter (LKB-Wallac, Turku).

Validation of the radioimmunoassay. The sensitivity of the assay, determined as the lowest standard that differed from the zero standard by twice the standard deviation of the zero standard, was 0.625 pmol per tube. Parallelism between standards in buffer and endogenous tammar mesotocin was determined by comparison of serial dilutions of a pool of plasma and a posterior pituitary extract from late pregnant tammars. The buffer standard curve was also compared with mesotocin standards in charcoal-stripped plasma and female plasma to assess interference from other compounds in the plasma samples that might affect antiserum binding. The accuracy of the assay was determined by adding known quantities of mesotocin to charcoal-stripped and female plasma. Non-specific binding tubes were included in each assay and did not exceed $1 \%$ of the total counts. Two sample pools of endogenous tammar mesotocin were prepared to evaluate precision. An extract of posterior pituitary (1:2000 dilution) represented a Quality Control High $(\mathrm{QCH})$ and male plasma provided a Quality Control Low (QCL). The interassay coefficient of variation ( $n=8$ assays) was $3.5 \%\left(\mathrm{QCH}, 1500 \mathrm{pmol}^{-1}\right)$ and 
$6 \%\left(\mathrm{QCL}, 18 \mathrm{pmol}^{-1}\right)$. The intra-assay coefficient of variation was $3.5 \%$.

Assay of prostaglandin $-F_{2 a}$ metabolite. Plasma PGFM concentrations were measured in $100 \mu \mathrm{l}$ aliquots by the method of Lewis et al. (1986). Sensitivity of the assay was $15.6 \mathrm{pg}$ per tube. The interassay coefficient of variation (CV) was $15.4 \%$ and the intra-assay $\mathrm{CV}$ was $3.4 \%(n=3$ assays).

\section{Statistical analyses}

Repeated measures analysis of variance was used to test for differences in plasma hormone concentrations between various stages of pregnancy. Differences in plasma hormone concentrations during parturition were analysed using paired $t$-tests because some blood samples were not taken at some time points.

\section{Results}

\section{Validation of the mesotocin assay}

Parallelism was established for mesotocin standards measured in assay buffer, charcoal-stripped plasma and female plasma. Addition of plasma to the standards caused a shift in the standard curve to the right. However, the slopes of both the log-logit transformed plasma curves were parallel and not significantly (analysis of covariance; $F=2.55, P=0.15$ ) different from that of the standard curve in buffer, nor was there any difference in the slopes of the standard curve in buffer and dilutions of female plasma or posterior pituitary extract high in endogenous mesotocin. Recovery of mesotocin added to both charcoal-stripped and female plasma was quantitative and linear (stripped plasma: $y=21.85+0.95 x$, female plasma: $y=14.08+0.87 x$, where $y=$ amount of mesotocin added, $x=$ amount of mesotocin recovered). This regression was significant in both instances $(P<0.05)$ with a correlation coefficient $(r)$ of 0.993 and 0.999 , respectively.

Pituitary content. A single immunoreactive peak, corresponding to the retention time for authentic mesotocin, was present in pituitary extracts separated by HPLC (Fig. I). No mesotocin immunoreactivity was present in the fractions corresponding to authentic oxytocin. Concentrations of mesotocin in the two pituitary glands obtained on day 25 of pregnancy were 2.8 and $2.4 \mu \mathrm{g}$ per pituitary, respectively.

Mesotocin during pregnancy. Four of the five animals from which daily blood samples were collected had pouch young on day 25 or day 26 after removal of pouch young but the exact time of birth was not recorded. Plasma mesotocin concentrations were in the range of $10-20 \mathrm{pmol}^{-1}$ throughout pregnancy in all four animals and in some samples were below the limit of sensitivity of the assay. There was no significant $(P>0.05)$ increase in basal mesotocin concentrations at any stage of pregnancy (Fig. 2). The remaining tammar was not pregnant. Plasma mesotocin concentrations in this animal were similar to those of pregnant tammars (mean throughout the 26 day sample period $11.4 \pm 1.7 \mathrm{pmol} \mathrm{l}^{-1}$ ).

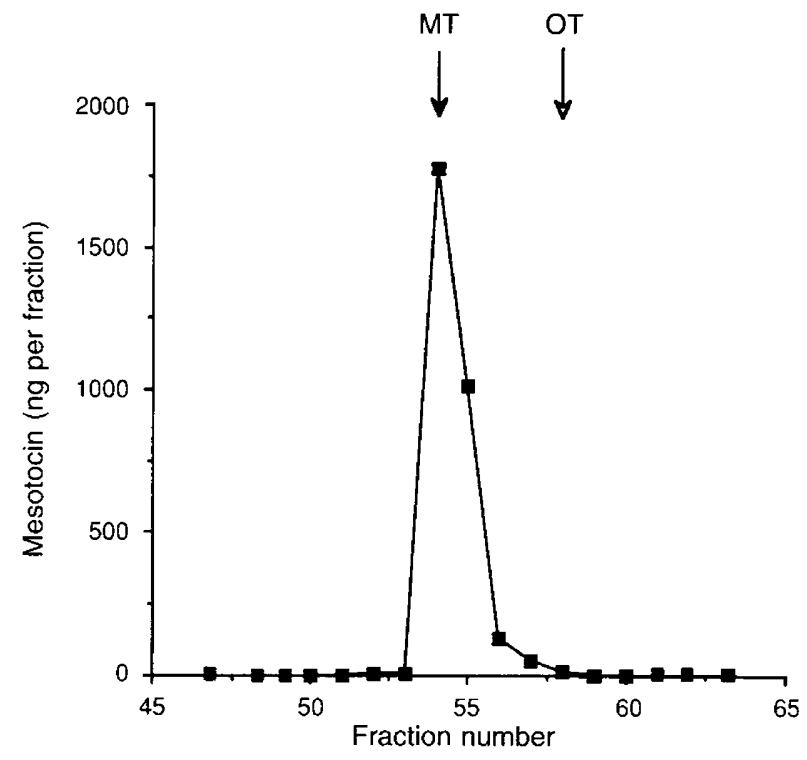

Fig. 1. Concentration of (a) mesotocin (MT) in the pituitary of the tammar wallaby on day 25 of pregnancy. Extracts were separated by HPLC and assayed. Retention times for authentic mesotocin and oxytocin (OT) are shown (arrows). Note that mesotocin is the only oxytocic neuropeptide in the tammar neurohypophysis.

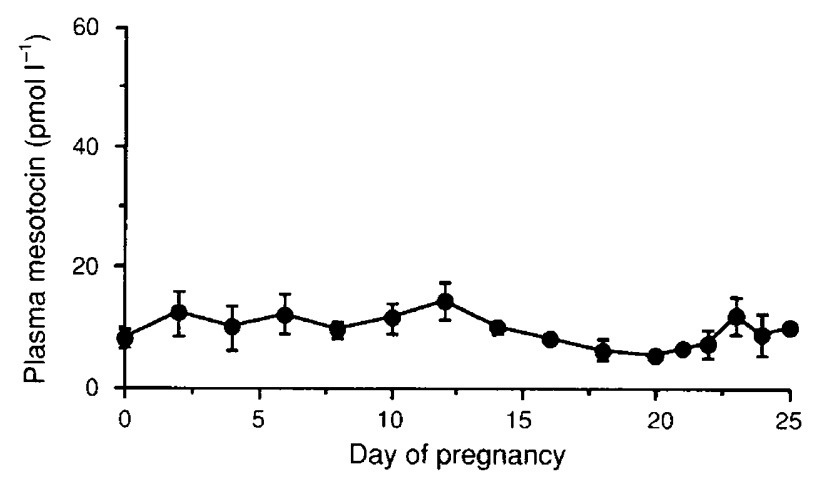

Fig. 2. Mean \pm SEM plasma concentrations of mesotocin throughout pregnancy in the tammar wallaby $(n=4)$.

Mesotocin during parturition. Mean basal mesotocin concentrations on day 19 of pregnancy were $11.6 \pm 6.6 \mathrm{pmol}^{-1}$ before the onset of blood sampling and did not differ significantly $(P>0.05)$ from other stages of pregnancy. Repeated blood sampling at intervals of 1 min did not stimulate mesotocin release in conscious pregnant tammars on day 19 of pregnancy. In all five animals, basal mesotocin concentrations remained below $18 \mathrm{pmol} \mathrm{I}^{-1}$ throughout the 20 min sampling period.

In Expt I, all six animals gave birth within the normal time, on day 25.6 \pm 0.4 . No increase in plasma PGFM was detected in three prepartum samples taken from individual animals between 10 and $45 \mathrm{~min}$ before birth, but in one animal, sampled $10 \mathrm{~min}$ before birth, plasma mesotocin reached $49 \mathrm{pmol}^{-1}$ and was increased above basal concentrations (Fig. 3a). There was a significant $(P<0.05)$ increase in plasma mesotocin immediately after delivery of the neonate, compared 

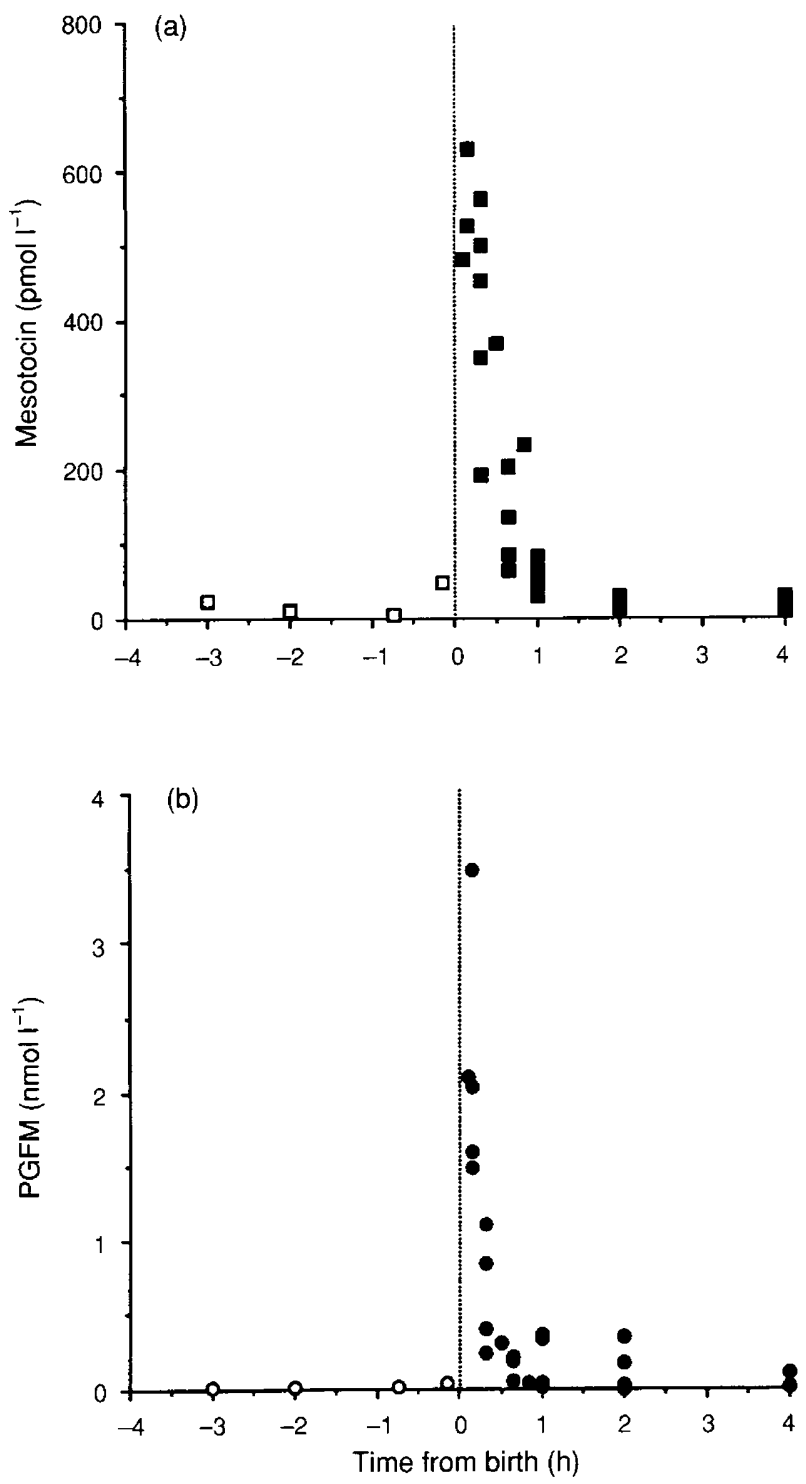

Fig. 3. Plasma concentration of (a) mesotocin and (b) prostaglandin $F_{2 a}$ metabolite (PGFM) in six tammar wallabies sampled around the time of birth. $(\sqsubset, 0)$ Samples taken before birth; $(\bullet, \bullet)$ samples taken after birth (:). Note the similar profiles of mesotocin and PGFM in the peripheral plasma during the peripartum period.

with values at $08: 00 \mathrm{~h}$ on day 25 of pregnancy $(<15 \mathrm{pmol}$ $\left.\mathrm{l}^{-1}\right)$, and this increase was maintained for at least $40 \mathrm{~min}$ postpartum (Fig. 3a). Two hours after birth, mesotocin concentrations had decreased to less than $20 \mathrm{pmol} \mathrm{l}^{-1}$. Peak mesotocin concentrations of $546.6 \pm 44.1 \mathrm{pmol} \mathrm{l}^{-1}$ were measured between 0 and $20 \mathrm{~min}$ postpartum. This coincided with a short-lived, significant $(P<0.05)$ peak in plasma PGFM $\left(2.1 \pm 0.4 \mathrm{nmol} \mathrm{l}^{-1}\right)$ immediately after birth that decreased to less than $0.3 \mathrm{nmol} \mathrm{l}^{-1}$ within $2 \mathrm{~h}$ postpartum (Fig. $3 \mathrm{~b}$ ).

In Expt II, six of the eight tammars gave birth on day $25.2 \pm 0.2$ and were successfully sampled at intervals of $1 \mathrm{~min}$ during parturition. The time of birth for these animals was highly synchronized (average time of day 14:51 $\pm 01: 35 \mathrm{~h}$ ). The latency from birth position to delivery of the neonate was $3.8 \pm 0.5 \mathrm{~min}$. As the latency to birth was within $4 \mathrm{~min}$ once animals adopted the birth position, only 1 blood sample from one animal was taken by chance $5 \mathrm{~min}$ prepartum. Plasma mesotocin concentrations in this sample were below the sensitivity of the assay (Fig. 4a). All six tammars sampled immediately after birth showed a significant $(P<0.05)$ increase in plasma mesotocin compared with basal values at 08:00 h on day 25 of pregnancy $\left(8.2 \pm 1.3 \mathrm{pmol}^{-1}\right)$. The profile of mesotocin release was similar in all six animals, but maximum concentrations varied between individuals (Fig. 4). Peak mesotocin concentrations of $516.7 \pm 108.1 \mathrm{pmol}^{-1}$ were observed I-2 min after birth of the fetus, remained over $300 \mathrm{pmol} \mathrm{I}^{-1}$ for at least $15 \mathrm{~min}$ and started to fall $20 \mathrm{~min}$ postpartum. At sixty minutes after birth, two of the six animals had increased mesotocin concentrations $\left(336.0 \pm 58.0 \mathrm{pmol} \mathrm{I}^{-1}\right)$, whereas in the other four, mesotocin values were $24.2 \pm 7.9 \mathrm{pmol} \mathrm{l}^{-1}$. The remaining two tammars did not adopt a birth position by day 28 RPY when continual observations ceased and therefore were not sampled. They were presumed not to be pregnant on day 32. Four of the eight animals mated within $48 \mathrm{~h}$ of birth.

\section{Discussion}

This study demonstrated a rapid increase in plasma mesotocin coincident with birth in the conscious tammar wallaby, which suggests that this peptide may have important functions associated with parturition. Plasma mesotocin concentrations remained low throughout pregnancy and did not increase at any stage of gestation or before birth. An increase in plasma mesotocin was observed only immediately after delivery of the neonate and was maintained for at least $15 \mathrm{~min}$ postpartum. The pattern of mesotocin release is similar to that of oxytocin release in eutherian mammals (Fuchs, 1985). In rabbits and rats, peak concentrations of oxytocin are associated with delivery of the first or second pup (Higuchi et al., 1985; O'Byrne et al., 1986). In cows, the highest oxytocin concentrations occur with rupture of fetal membranes and expulsion of the calf (Aurich et al., 1993). From the 14 tammars that gave birth, only five samples were obtained between 5 and $45 \mathrm{~min}$ before delivery. No increase in plasma PGFM was detected in any of these samples and there was an increase in mesotocin concentrations in only one sample obtained $10 \mathrm{~min}$ before birth (Expt I). The absence of an increase in plasma mesotocin and PGFM immediately before birth in this study may be due partly to the difficulty in predicting the onset of labour and to sampling frequently enough from the conscious tammars in the short period from the beginning of birth behaviour to the appearance of the neonate at the urogenital opening. With frequent sampling at intervals of $10-15 \mathrm{~s}$ in rabbits, O'Byrne et al. (1986) were able to show that a marked increase in oxytocin release occurs within $40-120 \mathrm{~s}$ of the expulsive phase of delivery; this was preceded by the rapid onset of bursts of accelerated discharge of the oxytocin neurones. It is therefore likely that the onset of mesotocin release in the tammar will occur minutes before delivery.

Bathgate and Sernia (1995b) suggest that animal handling and physical restraint may stimulate the release of mesotocin in possums. This was an important consideration in our study as the parturient tammars were lightly restrained in sacks for up to $20 \mathrm{~min}$ during sampling. This degree of handling did not 

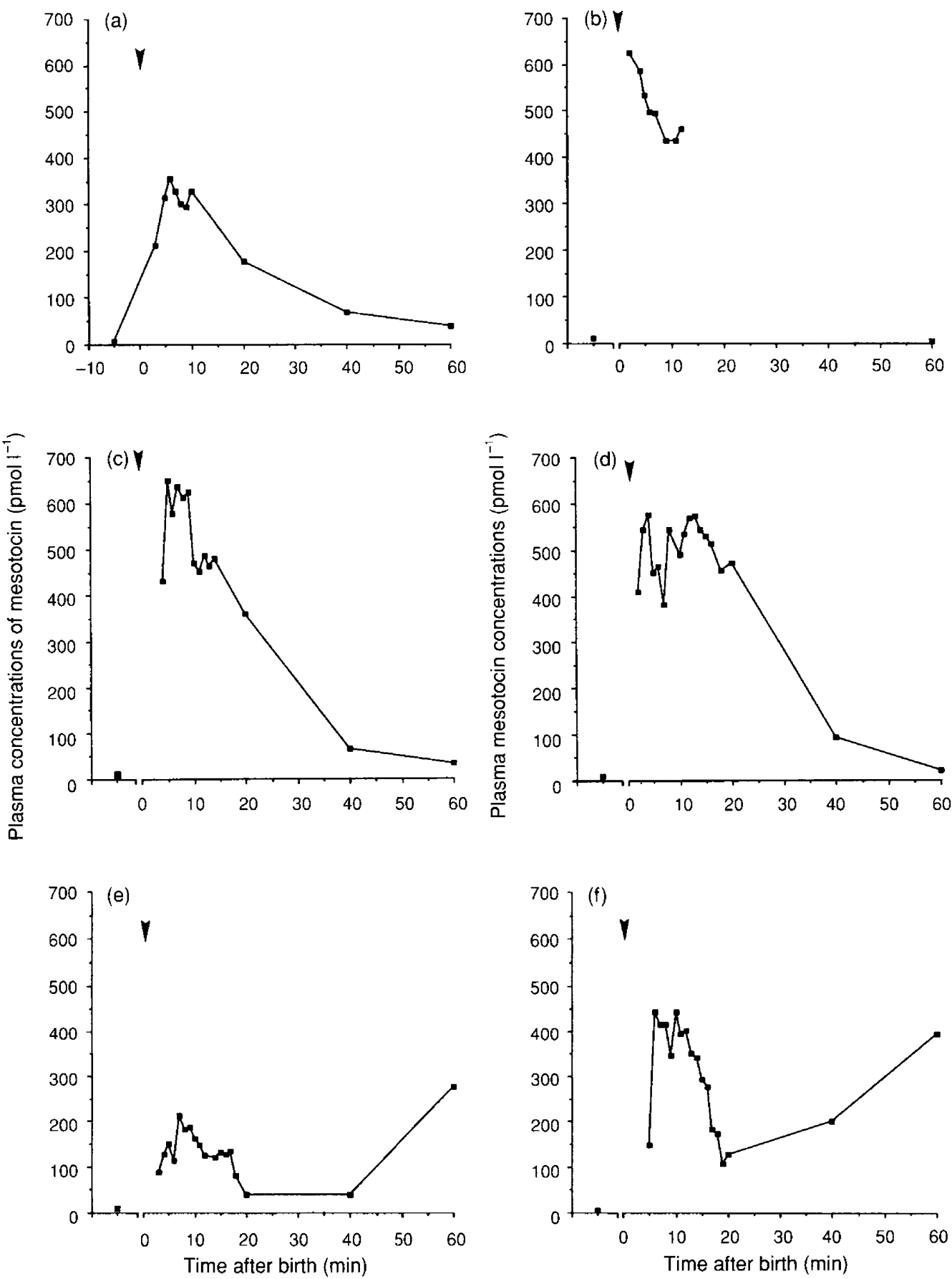

Fig. 4. Plasma mesotocin profiles during parturition in six individual tammars. Each datum point represents average mesotocin concentration measured in triplicate aliquots of plasma. Birth is indicated by the arrowhead. (a) Neonate was removed immediately after birth. (b)-(f) Neonates were attached to a teat within 20 min of delivery.

induce mesotocin release in conscious tammars as plasma mesotocin remained basal in control animals sampled on day 19 of pregnancy. Therefore, we conclude that the increase in plasma mesotocin observed at the time of birth was not induced by catching and light restraint. In addition, the procedure we used did not affect birth or postpartum oestrus. Bathgate and Sernia (1995b) also reported that haemorrhage corresponding to at least a $20 \%$ decrease in blood volume is a specific stimulus for mesotocin release in the possum. In our sampling regimen, a maximum of $15 \mathrm{ml}$ blood was taken over $20 \mathrm{~min}$, corresponding to $3.75 \%$ of the total blood volume of a $5 \mathrm{~kg}$ tammar. This sampling procedure did not have a hypovolaemic effect as mesotocin concentrations remained constant throughout the $20 \mathrm{~min}$ sampling time in the control experiment.

The concentrations of mesotocin in the late pregnant tammar pituitary are similar to those reported in other female and male marsupials (Bathgate et al., 1992). Earlier studies in 
pregnant tammars detected lower concentrations of mesotocin in pituitary extracts and no mesotocin in corpora lutea (Curlewis et al., 1988). Immunoreactive oxytocin has since been reported in luteal cells of the pregnant opossum (Krause et al., 1992) and mesotocin has been reported in possums during the early and mid-luteal phase (Sernia et al., 1994). However, in possums, the concentrations of mesotocin in the corpus luteum are low in comparison with the pituitary (Sernia et al., 1994). Therefore, we conclude that the maternal pituitary gland is the principal source of circulating mesotocin during parturition in the tammar.

Release of mesotocin from the posterior pituitary at birth in the tammar is likely to be associated with a burst of mesotocin neurone activity. Oxytocin release in rats is stimulated by vaginal or cervical distension (Higuchi et al., 1987). A similar mechanism involving stretching of the cervix during birth could stimulate mesotocin release from the tammar pituitary and thereby enhance contractions of the uterus. Other endocrine factors may also affect release of mesotocin. Prostaglandins are the principal mediators of parturition in tammars. Birth does not occur in animals treated with a prostaglandin synthase inhibitor during late gestation; postmature fetuses are retained in utero (Renfree et al., 1995). Imminent birth is preceded by characteristic birth behaviour which can be induced by prostaglandin $\mathrm{F}_{2 u}$ in the tammar (Hinds et al., 1990) and in the bandicoot and possum (Gemmell et al., 1992). A surge in plasma PGFM is measured immediately prepartum in these species (Lewis et al., 1986; Gemmell et al., 1987). Explants of tammar endometrial tissue produce prostaglandins $\mathrm{F}_{2 \alpha}$ and $\mathrm{E}_{2}$ in vitro and the basal rate of production increases threefold in the last 2 days of gestation (Shaw et al., 1994). This increase alone may be sufficient to stimulate uterine contractions. Prostaglandins could also provide the stimulus for mesotocin release. Exogenous injection of the prostaglandin $\mathrm{F}_{2 \alpha}$ analogue cloprostenol stimulates a prompt increase in oxytocin secretion in postpartum sows (Ellendorff et al., 1979) and late pregnant cows (Aurich et al., 1993). Preliminary data in anoestrous possums demonstrate that cloprostenol also increases plasma mesotocin (Bathgate et al., 1995). However, it is not clear whether endogenous prostaglandin $\mathrm{F}_{2 \alpha}$ has a similar effect on mesotocin release at parturition. In the study reported here, there was a positive association between circulating mesotocin and PGFM concentrations which suggests that there are important interactions between these two hormones. A large increase in plasma oxytocin is also temporarily associated with a surge of prostaglandin $\mathrm{F}_{2 \alpha}$ in parturient cows (Eley et al., 1981). Oxytocin stimulates the release of endometrial prostaglandin $\mathrm{F}_{2 \alpha}$ in nonpregnant cows (Lafrance and Goff, 1990) and pregnant sheep (Meier et al., 1995). Fuchs et al. (1992) suggest that endogenous oxytocin acts on bovine endometrial receptors to mediate the release of uterine prostaglandin $\mathrm{F}_{2 \alpha}$ shortly before parturition. Thus, an increase in circulating oxytocin or mesotocin might be expected to precede PGFM. Recent work in the late pregnant tammar shows that disruption of the action of the mesotocin receptors delays the surge in plasma PGFM (Renfree t al., 1996); this is strong evidence for an interaction between mesotocin and prostaglandin release.

The present study demonstrates that mesotocin is released during, or immediately after, parturition in the tammar wallaby and strengthens the hypothesis that mesotocin has a uterotonic role in marsupials, similar to that of oxytocin in eutherians. Marsupials are the only mammals possessing mesotocin (Acher and Chauvet, 1995), and given the functional similarity with oxytocin, our data further support the idea that oxytocin is the 'ancestral' precursor for marsupial mesotocin. Increased mesotocin does not appear to be crucial for the initiation of parturition, as plasma concentrations are low immediately prepartum and birth can proceed in the absence of functional mesotocin receptors (Renfree et al., 1996). Both mesotocin and prostaglandins are likely to facilitate delivery by causing contractions of the myometrium and the birth canal. It remains to be demonstrated whether mesotocin release precedes or regulates prostaglandin synthesis or vice versa in parturient marsupials.

The authors thank S. Birkett (Dept of Anatomy, University of Bristol, Bristol) for providing the mesotocin antiserum. They also thank $G$. Shaw and R. Bathgate for their helpful suggestions and criticism of the manuscript, R. Moyle for his excellent care of the animals and the 'wallabologists' for assistance with watching for births and collection of blood samples. The animals were held under permits numbers RP92098 and RP92099 from the Department of Conservation and Natural Resources, Victoria, Australia. The authors are grateful to the Australian Research Council for financial support for this work

\section{References}

Acher R (1990) Structure, evolution and processing adaptation of neurohypophysial hormone-neurophysin precursors In Progress in Comparative Endocrinology pp 1-9 Eds A Epple, CG Scanes and MH Stetson. Wiley, New York

Acher R and Chauvet J (1995) The neurohypophysial endocrine regulatory cascade: precursors, mediators, receptors, and effectors Frontiers in Neuroendocrinology 16 237-289

Antonijevic IA, Douglas AJ, Dye S, Bicknell RJ and Leng G (1995) Oxytocin antagonists delay the initiation of parturition and prolong its active phase in rats Joumal of Endocrinology 145 97-103

Aurich JE, Dobrinski l, Hoppen H-O and Grunert E (1993) Stimulation of release of $\beta$-endorphin and oxytocin by prostaglandin $F_{2 i a}$ in cattle at parturition Journal of Reproduction and Fertility 97 161-166

Bathgate RAD and Sernia C (1995a) Characterization of vasopressin and oxytocin receptors in an Australian marsupial Journal of Endocrinology $\mathbf{1 4 4}$ 19-29

Bathgate RAD and Sernia C (1995b) Regulation of neurohypophysial hormone secretion in an Australian marsupial American Joumal of Physiology 268 R1319-1326

Bathgate RAD, Sernia C and Gemmell RT (1990) Mesotocin in the brain and plasma of an Australian marsupial, the brushtail possum (Trichosurus vulpecula) Neuropeptides 16 121-127

Bathgate RAD, Sernia C and Gemmell RT (1992) Mesotocin and oxytocin in the brain and plasma of an Australian marsupial, the northern brown bandicoot Isoodon macrourus Comparative Biochemistry and Physiology 102A 43-48

Bathgate RAD, Parry LJ, Fletcher TP, Shaw G, Renfree MB, Gemmell RT and Sernia C (1995) Comparative aspects of oxytocin-like peptides in marsupials In Oxytocin: Cellular and Molecular Approaches in Medicine and Research Advances in Experimental Medicine and Biology 395 639-655 Eds R Ivell and JA Russell. Plenum Press, New York

Chan WY and Chen D (1992) Myometrial oxytocin receptors and prostaglandin in the parturition process in the rat Biology of Reproduction 46 58-64

Chauvet J, Hurpet D, Michel G, Chauvet M-T and Acher R (1984) Two multigene families for marsupial neurohypophysial hormones? Identification of oxytocin, mesotocin, lysipressin and arginine vasopressin in the North American opossum Didelphis virginiana Biochemical and Biophysical Research Communications 123 306-311

Chauvet J, Hurpet D, Colne T, Chauvet M-T and Acher R (1985) Neurohypophyseal hormones as evolutionary tracers: identification of oxytocin, lysine vasopressin and arginine vasopressin in two South American opossums, 
Didelphis marsupialis and Philander opossum General and Comparative Endocrinology 57 320-328

Curlewis JD, Renfree MB, Sheldrick EL and Flint APF (1988) Mesotocin and luteal function in macropodid marsupials Journal of Endocrinology 117 $367-372$

Eley DS, Thatcher WW, Head HH, Collier RJ and Wilcox CJ (1981) Periparturient endocrine changes of conceptus and maternal units in Jersey cows bred for milk yield Journal of Dairy Science 64 296-311

Ellendorff F, Forsling M, Parvizi N, Williams H, Taverne M and Smidt D (1979) Plasma oxytocin and vasopressin concentrations in response to prostaglandin injection into the pig Journal of Reproduction and Fertility 56 573-577

Fletcher TP, Shaw G and Renfree MB (1990) Effects of bromocriptine at parturition in the tammar wallaby, Macropus engenii Reproduction, Fertility and Development 2 79-88

Fraker PJ and Speck JC (1978) Protein and cell membrane iodinations with sparingly soluble chloroamide, 1,3,4,6-tetrachloro-3 $\alpha, 6 \alpha$-diphrenylglycoluril, Biochemical and Biophysical Research Communications 80 849-857

Fuchs A-R (1985) Oxytocin in animal parturition In Oxytocin: Clinical and Laboratory Studies pp 207-235 Eds JA Amico and AG Robinson. Elsevier Science Publishers BV, Amsterdam

Fuchs A-R (1990) Oxytocin and oxytocin receptors: maternal signals for parturition In Uterine Contractility: Mechanisms of Control pp 177-190 Ed. RE Garfield. Serono Symposia, Norwell

Fuchs A-R and Dawood MY (1980) Oxytocin release and uterine activation during parturition in rabbits Endocrinology 107 1117-1126

Fuchs A-R, Romero R, Keefe D, Parra M, Oyarzun E and Behnke E (1991) Oxytocin secretion and human parturition: pulse frequency and duration increase during spontaneous labour in women American Journal of Obstetrics and Gynecology 165 1515-1523

Fuchs A-R, Helmer H, Behrens O, Liu H-C, Antonian L, Chang SM and Fields MJ (1992) Oxytocin and bovine parturition: a steep rise in endometrial oxytocin receptors precedes onset of labour Biology of Reproduction 47 937-944

Gemmell RT, Hughes RL and Jenkin G (1987) Comparative studies on the humoral profiles of progesterone and prostaglandin $F$ metabolite in the possum Trichosurus vulpecula In Possums and Opossums, Studies in Evoiution pP 279-291 Ed. M Archer. Surrey Beatty and Sons Pty Ltd, Sydney

Gemmell RT, McFadyen AS and Rose RW (1992) Induction of parturient behaviour in possums (Marsupiala: Phalangeridae) and bandicoots (Marsupiala: Permalidae) Australian Mammalogy 14 133-135

Hearn J (1973) Pituitary inhibition of pregnancy Nature 241 207-208

Higuchi T, Honda K, Fukuoka T, Negoro H and Wakabayashi K (1985) Release of oxytocin during suckling and parturition in the rat Journal of Endocrinology $105339-346$

Higuchi T, Uchide K, Honda K and Negoro H (1987) Pelvic neurectomy abolishes the fetus-expulsion reflex and induces dystocia in the rat Experimental Neurology 96 443-455

Hinds LA (1990) Control of pregnancy, parturition and luteolysis in marsupials Reproduction, Fertility and Development 2 535-552

Hinds LA, Tyndale-Biscoe CH, Shaw G, Fletcher TP and Renfree MB (1990) Effects of prostaglandin and prolactin on luteolysis and parturient behaviour in the non-pregnant tammar, Macropus eugenii Journal of Reproduction and Fertility 88 323-333

Krause WJ, Sherman DM and Samson WK (1992) Immunohistochemical evidence for the presence of oxytocin in the opossum corpus luteum Acta Histchemica 92 190-195

Lafrance $\mathrm{M}$ and Goff AK (1990) Control of bovine uterine $\mathrm{PGF}_{24}$ release in vitro Biology of Reproduction 42 288-293

Lewis PR, Fletcher TP and Renfree MB (1986) Prostaglandins in the peripheral plasma of tammar wallabies during parturition Journal of Endocrinology 111 103-109
Meier S, Lau TM, Jenkin G and Fairclough RJ (1995) Oxytocin-induced prostaglandin $F_{2 u}$ release and endometrial oxytocin receptor concentrations throughout pregnancy in ewes Journal of Reproduction and Fertility 103 233-238

O'Byrne KT, Ring JPG and Summerlee AJS (1986) Plasma oxytocin and oxytocin neurone activity during delivery in rabbits Journal of Physiology $\mathbf{3 7 0}$ 501-513

Renfree MB and Young IR (1979) Steroids in pregnancy and parturition in the marsupial, Macropus engenii Journal of Steroid Biochemistry 11 515-522

Renfree MB, Fletcher TP, Blanden DR, Lewis PR, Shaw G, Gorden K, Short RV, Parer-Cook E and Parer D (1989) Physiological and behavioural events around the time of birth in macropodid marsupials In Kangaroos, Wallabies and Rat Kangaroos pp 323-337 Eds G Grigg, P Jarmen and I Hume. Surrey Beatty and Sons Pty Ltd, Sydney

Renfree MB, Shaw G and Fletcher TP (1995) Evidence for the essential role of prostaglandins for parturition in a marsupial, Macropus engenii Journal of Reproduction and Fertility 102 433-446

Renfree MB, Parry LJ and Shaw G Infusion with an oxytocin receptor antagonist delays parturition in a marsupial Journal of Reproduction and Fertility (in press)

Rouille Y, Chauvet M-T, Chauvet J and Acher R (1988) Dual duplication of neurohypophysial hormones in an Australian marsupial: mesotocin, oxytocin, lysine vasopressin and arginine vasopressin in a single gland of the northern bandicoot (Isoodon macrourus) Biochemical and Biophysical Research Communications 154 346-350

Saito N, Kinzler S and Koike TI (1991) Arginine vasotocin and mesotocin levels in theca and granulosa layers of the ovary during the oviposition cycle in hens (Gallus domesticus) General and Comparative Endocrinology 79 $54-63$

Sawyer WH and Pang PKT (1979) In Hormones and Evolution pp 493-523 Ed. EJW Barrington. Academic Press, London

Schellenberg J-C (1995) The effect of oxytocin receptor blockade on parturition in guinea pigs Journal of Clinical Investigation 95 13-19

Sernia C, Thomas WG and Gemmell RT (1991) Oxytocin receptors in the mammary gland and reproductive tract of a marsupial, the brushtail possum (Trichosurus vulpecula) Biology of Reproduction 45 673-679

Sernia C, Bathgate RAD and Gemmell RT (1994) Mesotocin and arginine vasopressin in the corpus luteum of an Australian marsupial, the brushtail possum (Trichosurus vulpecula) General and Comparative Endocrinology 93 197-204

Shaw G (1983a) Effect of $\mathrm{PGF}_{2 u}$ on uterine activity, and concentrations of 13,14-dihydro-15-keto-PGF ${ }_{2 u}$ in peripheral plasma during parturition in the tammar wallaby (Macropus engenii) Journal of Reproduction and Fertility 69 429-436

Shaw G (1983b) Pregnancy after Diapause in the Tammar Wallaby, Macropus eugenii PhD Thesis, Murdoch University, Perth, Western Australia

Shaw G, Gehring H and Bell EC (1994) Prostaglandin production by endometrium in late pregnant tammar wallabies Proceedings of the 26th Annual Meeting of the Australian Society for Reproductive Biology. Brisbane. Abstract 46

Short RV, Flint APF and Renfree MB (1985) Influence of passive immunization against gonadotrophin-releasing hormone on embryonic diapause and parturition in the tammar wallaby, Macropus eugenii Journal of Reproduction and Fertility 75 567-575

Soloff MS (1985) Oxytocin receptors and mechanisms of oxytocin action In Oxytocin: Clinical and Laboratory Studies pp 259-276 Eds JA Amico and AG Robinson. Elsevier Science Publishers BV, Amsterdam

Tyndale-Biscoe CH (1966) The marsupial birth canal Symposium of the Zoological Society of London 15 233-250 